\title{
DE FORTIFICAR LA VOLUNTAD A DESARROLLAR LA PERSONALIDAD: \\ CUERPO Y EMOCIONES EN LA \\ EDUCACIÓN CHILENA (C.1900-C.1950)*
}

Pablo Toro Blanco ${ }^{1}$

RESUMEN: El artículo aborda, sucintamente, algunos aspectos de las vinculaciones entre cuerpo y emoción que, respecto al ámbito educacional chileno, fueron tematizadas por distintos actores a través del período en estudio. Ello supone apreciar cambios desde aquellos enfoques centrados en el control y disciplina del cuerpo (perspectiva hegemónica en el contexto educacional del siglo XIX) hacia nuevas comprensiones de la "naturaleza" de los estudiantes (entendida desde la psicología) y, en consecuencia, a un modo diferente de abordar los atributos de su subjetividad y sus correlatos con lo corporal.

Palabras clave: Educación física. Cuerpo. Educación chilena. Emociones.

\footnotetext{
*Este texto es parte del Proyecto Fondecyt Regular 1140604 (2014-2017), del cual el autor es investigador responsable. Agradezco la valiosa ayuda prestada por mis ayudantes Javiera Letelier Carvajal y Luis Felipe Caneo Meneses.

${ }^{1}$ Universidad Alberto Hurtado, Santiago, Chile. E-mail: ptoro@uahurtado.cl DOI: 10.1590/CC0101-32622018177807
} 


\title{
From strengthening the will to develop the personality: body and emotion in the Chilean education (c.1900-c.1950)
}

\begin{abstract}
The article briefly discusses some aspects of the linkages between body and emotion which, regarding the Chilean educational field, were analyzed by different actors throughout the studied period. This implies to observe changes from those approaches focused on the control and discipline of the body (hegemonic perspective in the educational context of the nineteenth century) and new understandings of students' "nature" (from psychology) and, consequently, to a different way of approaching the attributes of their subjectivity as well as their embodiment.
\end{abstract}

Keywords: Physical education. Body. Chilean education. Emotions.

\section{INTRODUCCIÓN}

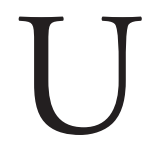

n día de junio de 1872 Domingo Grez, estudiante de quinto ańo de Humanidades en el Instituto Nacional, fue poseído por la ira. De acuerdo con el informe enviado al Ministerio de Instrucción Pública, desde hace días se venían repitiendo conflictos entre los alumnos y sus inspectores, lo que había alterado el rígido orden que se asumía que debía imperar en el principal establecimiento de educación secundaria del país. Domingo sintió que algo cedía en su interior, rompiendo los diques de la contención que le había sido enseñada y, quizás sin ser soberano sobre sí mismo, "se desató en improperios contra él [el inspector Lindor Frías] profiriendo palabras injuriosas y amenazas hasta el extremo de decirle ii "te mato carajo!!" teniendo crispados los puños" (TORO BLANCO, 2009, p. 425). La ira se hizo palabra e insulto y también se tradujo en su cuerpo: se manifestó en esos puńos cerrados, amenazantes, que tradujeron con fidelidad su estado interior. No obstante, la amenaza quedó solamente en eso y los puños de Domingo finalmente volvieron a convertirse en esas blandas palmas juveniles a las que sus profesores e inspectores propinaban, 
en ocasiones, dolorosos golpes con el guante (especie de pequeño látigo para el castigo de los desvaríos estudiantiles).

El episodio de ira del joven Grez quedaría archivado, desde entonces, en el repertorio de incidentes con mérito suficiente para ser informados a las autoridades. Convertido en hecho excepcional, sería decodificado por un sistema de interpretación de la naturaleza juvenil que le indicaba a los adultos a su cargo que Domingo era una víctima (no por ello totalmente inocente) de la incapacidad de refrenar el "mal espíritu" latente que habitaba en él y sus compañeros y que sus educadores intentaban domeñar, auxiliados de una batería de manuales que enfatizaban el uso apropiado (político o aparente, como también se decía) del cuerpo, en el marco conceptual de la urbanidad. Esa fuerza destructiva requería ser combatida, de acuerdo a las categorías de la época, con disciplina y formación de la voluntad. En ello estaba en juego una comprensión de los afectos o emociones en que se les abordaba necesariamente como situaciones de presión, exceso o, de acuerdo a la caracterización presentada por Solomon (2007), como parte de un modelo hidráulico en el que se encuentran en proceso de ebullición esperando reventar y salir a la superficie. Prevenir esos estallidos devastadores requeriría considerar ecuaciones saludables y, en el lenguaje de época, moralizadoras entre educación, cuerpo y emoción, para las que la sublimación de la pasión juvenil resultaba indispensable. Ello era detectado muy tempranamente en la educación chilena decimonónica. Francisco Fierro, rector del Liceo de Concepción, en 1855 explicaba a las autoridades centrales por qué había implementado actividades gimnásticas en su plantel. Argumentaba que los ejercicios corporales

"en un colegio de instrucción literaria están llamados principalmente a desarrollar el físico de los alumnos sustituyendo las mayoría de las veces a una organización débil y enfermiza, una musculación robusta y vigorosa, dando más energía a los sentidos, estableciendo ese sistema de equilibrio que debe existir entre las facultades morales y corporales" (TORO BLANCO, 2009, p. 430-431). 
El episodio de Domingo y su ira, así como la visión del rector Fierro sobre el valor moralizador del ejercicio físico, se inscriben en un fenómeno histórico (las relaciones entre cuerpo y educación) que en Chile ha experimentado una saludable renovación en años recientes (MARTÍNEZ FERNÁNDEZ, 2011; DURÁN, 2014; SERRANO; PONCE DE LEÓN; RENGIFO, 2012). Parte de ello tiene que ver con el hecho de que la creciente preocupación científica por el cuerpo tuvo como escenario privilegiado, a guisa de laboratorio, al mundo escolar y, por ende, terminó por constituir a los registros escolares en una de las fuentes más sistemáticas, a lo largo del siglo XX, para la historiografía nacional que, en general, está interesada en el cuerpo (ROJAS FLORES, 2009, p. 117). Cabe señalar que buena parte de la atención se ha dirigido prioritariamente hacia el campo más explícito de interfaz entre cuerpo y enseñanza: la educación física, a la que se ha comprendido prioritariamente como un dispositivo curricular cuya implantación tuvo como propósito fundamental la normalización de la infancia. El proceso de instalación de la educación física como un campo legitimado pedagógicamente en el país encuentra sus hitos principales en las últimas décadas del siglo XIX y las primeras del XX. Los primeros pasos de la educación física (o gimnasia, en el vocabulario de la época) también han merecido atención en historiografías educacionales con un mayor desarrollo que el chileno como, por ejemplo, Argentina y Brasil (SCHARAGRODSKY, 2008; TABORDA DE OLIVEIRA, 2006). En el primero de los textos señalados es posible encontrar, además, estudios que ilustran los orígenes de la educación física también en los casos de Colombia y Brasil. Por su parte, el libro organizado por Marcus Aurelio Taborda de Oliveira aborda, mediante artículos monográficos de varios autores, distintas dimensiones del desarrollo de la educación física en Brasil, atendiendo a múltiples focos de interés aglutinados en torno al propósito de la escuela de modelar el cuerpo, por lo que se propone, entre otros fines, "discutir el proceso de conquista de corazones y mentes para la causa republicana” a través de los siglos XIX y XX ${ }^{1}$ (TABORDA DE OLIVEIRA, 2006, p. 5). En la producción existente para el caso chileno predomina el interés por los aspectos disciplinarios, nacionalizadores e higiénico-sanitarios asociados a la implantación de la educación física en escuelas y liceos en el período ya señalado (DURÁN, 2014). Ello es consistente con las 
formulaciones globales de la historia del cuerpo que observan a la gimnasia o educación física como un espacio de establecimiento de orden mediante el manejo colectivo del cuerpo (CORBIN et al., 2005).

Pese al acervo señalado, se dispone de un conjunto menos numeroso de estudios que aborden las relaciones entre cuerpo y educación desde la matriz tanto temática como cronológica que corresponde al propósito de este artículo: introducir una mirada analítica a las vinculaciones establecidas, desde el campo de la educación, entre cuerpo y emociones en el contexto de la enseñanza escolar de adolescentes y jóvenes, a través de un período que se extiende por cerca de medio siglo. Ello supone, por cierto, establecer diálogos con los enfoques centrados en el control y disciplina del cuerpo, tema más visible (o de mayor espectacularidad) en el contexto del siglo XIX, como se ha constatado, a propósito del trayecto de discusiones que llevaron a la abolición del castigo físico en la enseñanza secundaria (TORO BLANCO, 2014). Sin embargo, implica también introducirse en un análisis de las modificaciones en la interacción tanto corporal como emotiva entre profesores y estudiantes, proceso que se va manifestando paralelamente al desarrollo de la profesionalización de la pedagogía en Chile, a partir del último cuarto del siglo XIX (TORO BLANCO, 2012). Por ello, es apropiada la inserción de las dos categorías polares que incorpora el título de este artículo: voluntad y personalidad, en tanto reflejan comprensiones diferentes de la "naturaleza" de los estudiantes y, en consecuencia, de los atributos de su subjetividad: principalmente con foco en lo normativo y moral, en el primer caso; en clave psicológica, en el segundo. También suponen, ciertamente, correlaciones distintas con sus cuerpos.

Para satisfacer su propósito, este artículo se sustenta primordialmente, desde el punto de vista de su material de estudio, en la consulta a textos de especialistas en educación (principalmente del área de la psicología y sociología educacional), complementada con reportes de profesores, orientadores y directivos de escuelas secundarias y disposiciones oficiales. Previamente a elaborar el análisis de esas fuentes, se recurre brevemente a algunos autores y conceptos de referencia que remiten, en términos generales, al campo de la historia de las emociones. Así, empleando una metodología histórica basada 
en la interpretación de las fuentes en perspectiva hermenéutica, este estudio privilegia un asunto específico: los cambios en la conceptualización sobre el cuerpo estudiantil en la literatura educacional durante el período bajo análisis y las atribuciones de sentido emocional que se formulan al respecto.

\section{CUERPO Y EMOCIONES: BREVES CONSIDERACIONES}

Prescindiendo de una discusión mayor acerca de la naturaleza de las emociones, asunto que rebasa las posibilidades de este texto, sí parece necesario precisar escuetamente algunas ideas fundamentales para una mejor comprensión del problema en estudio. En tal sentido, se requiere indicar que un abordaje histórico a las emociones aparece como posible en la medida que no se las entienda como si fueran meros actos reflejos que se manifiestan en un hecho físico o lingüístico (el rubor en el rostro, propio de la vergüenza, por ejemplo), sino que se les asuma como realidades culturales sobre las que sus entornos históricos y culturales influyen, ya sea permitiendo su expresión, reprimiéndola, encausándola y, en cualquier caso, dándole un sentido contextual (MATT; STEARNS, 2014, p. 2). En la medida que se les remite a tal condición de hechos culturales, pierden aquellos atributos de universalidad que ciertas interpretaciones les suponían (como, por ejemplo, la de Charles Darwin en el siglo XIX, que, a partir de sus investigaciones, estableció taxonomías de alcance universal sobre las emociones). Vale decir, la expresión del dolor o la alegría no tienen un único repertorio, pese a que existan ciertas demostraciones somáticas mayoritariamente presentes en uno y otra, porque siempre está en juego la decodificación contextual que se haga de esas manifestaciones: el llanto de un joven estudiante es contingente a su marco de enunciación y no tiene siempre el mismo origen, sentido, uso y efecto. De tal modo, a las emociones hay que leerlas en su gramática temporal. Eso mismo es lo que las hace históricas. Por lo tanto, mirarlas como algo más que un mero circuito de estímulo-respuesta; analizarlas como encarnadas, o sea, expresadas en gestos corporales o materiales; entenderlas como parte del proceso de evaluación para la acción de 
parte de distintos agentes y, por último, explorar sus relaciones con construcciones normativas o morales son, a lo menos, cuatro puntos que vale la pena despejar cuando se intenta plantear una mirada histórica a ellas (PLAMPER, 2015, p. 39). El último ítem mencionado es especialmente significativo cuando se dirige la mirada al trinomio cuerpo-emoción-educación.

En este texto se enfoca a los discursos y concepciones sobre el cuerpo de los estudiantes no solamente a partir de sus dimensiones disciplinarias e higiénicas, sino que asumiendo de que ellos son productos y productores de acciones emocionales y se encuentran situados en un contexto histórico y cultural que les da su legibilidad específica. Por ende, se adapta como criterio de base la idea de que "las emociones entonces no son solamente expresadas sino también aprendidas a través del cuerpo, el que no es el opuesto de la cultura, sino que un sitio en que ella se ejecuta"2 (PERNAU, 2014). De tal modo, siguiendo las perspectivas de superación del binomio mente-cuerpo y agregando a ello la expectativa de no reducir los fenómenos emocionales solamente a sus expresiones lingüísticas, se emplea en estas páginas las propuestas de autoras como Monica Scheer, que consideran que las emociones se materializan, en tanto aplicaciones (y por ende devienen en históricas y culturales), a través del cuerpo, mediante "prácticas emocionales" que terminan constituyendo un habitus (en referencia a Bourdieu). De tal modo, "se necesita la repetición constante no solamente para el significado de los sentimientos, sino que también para su encarnación. Por ende, los procesos de materialización se comprenden mejor como procesos de sedimentación"3 (PASCAL EITLER; SCHEER apud PLAMPER, 2015, p. 137).

Es importante agregar, finalmente, a estas breves referencias de orden conceptual que en la materialización de lo emocional a través del cuerpo, como un producto de rutinas que se aprenden, se debe considerar también la interacción entre los cuerpos, su distancia prescrita o su posible cercanía en virtud de inducciones ya sea morales o psicológicas. Las emociones, devenidas en realidades corporales, también tienen (en tanto interpersonales) un componente proxémico, o sea, relacionado con el uso del espacio propio que los actores realizan y sus percepciones sobre éste, especialmente 
en función de la distancia y la proximidad ${ }^{4}$. El afecto, entendido como cariño, fue transformando la proxémica escolar desde una realidad de distancia corporal asumida como deseable y natural hacia un contacto físico que, en ocasiones, fue entendido como una virtuosa confusión momentánea de roles. Algo de eso se insinuaba ya a inicios de siglo, cuando un profesor argumentaba a favor de lazos más cercanos entre estudiantes y profesores pues, de acuerdo a su punto de vista

\begin{abstract}
¿Desde cuándo los superiores no pueden mezclarse con sus subalternos en momentos de gusto y expansión? Si esto fuera una verdad, resultaría que la mayor desgracia para el hombre sería ser una autoridad, puesto que por ese solo hecho quedaba aislado de entre sus semejantes y a mayor abundamiento cuando éstos gozan, cuando son felices (VELASCO, 1903, p. 169).
\end{abstract}

Años después, en el campo específico de la educación física, un especialista relevaba la necesidad de que los maestros pudieran llegar a ser para sus estudiantes "el amigo más tierno que pueda consultar, el más alegre compañero de juegos i diversiones i al mismo tiempo un camarada justo i severo" (MARTÍNEZ, 1916, p. 56-57).

\title{
EL TRINOMIO CUERPO-EMOCIÓN-EDUCACIÓN EN MEDIO SIGLO DE EDUCACIÓN CHILENA
}

Varios elementos de la herencia del siglo XIX respecto a las relaciones entre cuerpo y emoción, asentadas en el campo educativo, se internaron en las primeras décadas de la nueva centuria. Así, por ejemplo, el énfasis de la gimnasia decimonónica chilena en promover ejercicios vigorizantes, seriados, orientados a fortalecer la salud e higiene de niños y jóvenes se combinó con un tono marcial, especialmente bajo el influjo de la doctrina alemana respecto a la educación del cuerpo. El paralelo establecido entre la salud y disposición 
física apropiada de la juventud y el bienestar de la Nación, proyección de referencias a una suerte de volkgeist criollo, se mantuvo durante las primeras décadas del siglo XX, en un contexto en el que el los enfoques higienistas cobraban especial importancia como doctrinas interpretativas de las condiciones de una sociedad con altos grados de pauperismo. De tal modo, se prolongó el foco de una educación del cuerpo en perspectiva de ser insumo para combatir los temidos males sociales. Por ello es que, al decir de un investigador reciente del tema, "la enseñanza de la educación física cobró importancia como signo de una transformación morfológica promotora del bienestar sanitario de la población y del crecimiento de la nación" (MARTÍNEZ FERNÁNDEZ, 2011, p. 102).

En el sentido recién indicado puede citarse la opinión de Guillermo Martínez, Visitador de Educación Física de las Escuelas Públicas y Normales de Hombres, formado en el Instituto Central y Real de Gimnasia de Estocolmo. Martínez fue un entusiasta promotor de formas paramilitarizadas de educación física juvenil como, por ejemplo, el Tiro Escolar (TORO BLANCO, 2016, p. 83). Dando cuenta ya del peso de términos provenientes desde la ciencia antes que solamente del ámbito de la moral, actitud que cada vez sería más preponderante en los analistas conforme avanzó el siglo, Martínez sostenía que

el ejercicio i las actividades psicológicas que provoca, fortifican la voluntad del niño [...] Es, pues, inmensa la importancia del efecto psicológico de los ejercicios corporales [...]. Es la educación física la que desarrolla, educa i fortifica la voluntad i forma el carácter real que el alumno aplica en su vida práctica (MARTÍNEZ, 1916, p. 56-57).

En la visión de Martínez los ejercicios corporales operaban sobre la psicología (todavía entendida como carácter) de los niños y jóvenes, apareciendo así ya una lectura en que cuerpo y emoción adquirían un nuevo balance: la actividad física ya no era concebida principalmente como un desfogue emocional, un 
encausamiento requerido para restar presión a atávicas tendencias destructivas que yacían en el interior de los alumnos, en espera de un punto de ebullición.

Sería ya desde la década de 1930 que se apreciaría con más nitidez la emergencia de un discurso educacional sobre el cuerpo que, sin alejarse totalmente de las preocupaciones sanitarias por el bienestar de la colectividad (o Defensa de la Raza, como se le conceptualizó desde el Estado hacia fines de ese decenio), fue redefiniendo la relación entre el ejercicio físico y las dimensiones psicológicas, anímicas y emocionales de los estudiantes. De hecho, un representante de la tendencia a favor de la gimnasia de inspiración alemana, Leotardo Matus, en sus reflexiones sobre el valor del ejercicio corporal veía la necesidad de incluir como un factor de su éxito el consenso activo de los estudiantes, expresado en su alegría y la constatación emocional del bienestar que la educación física les debía reportar. Indicaba Matus que "es tan grande la importancia que tiene el placer en la práctica de los movimientos, que cuando éste falta el ejercicio se convierte en trabajo forzado que debilita el sistema nervioso en vez de robustecerlo" (MATUS, 1932, p. 3).

En el contexto de los años 30 era difícil que los analistas respecto a la educación física pudieran ser inmunes al influjo de los discursos nacionalistas y colectivistas en boga. Como ha sido señalado por Barbara Keys en referencia a las políticas hacia el cuerpo dispuestas bajo el nazismo y el régimen estalinista, ellos "apuntaban al cuerpo como un medio para alcanzar la mente, intentando utilizar la educación física para reforzar patrones de pensamiento e inculcar características psicológicas que la agenda estatal promovía” (KEYS, 2009, p. 305)5. En la apelación a la masa había una intención de inducir estados emocionales específicos funcionales a los lineamientos políticos propiciados por el Estado. Por lo mismo, parte del discurso en torno al carácter nacional cultivado y expresado mediante la formación escolar del cuerpo se mantuvo. Aspectos de ello se manifiestan en un discurso pronunciado en 1937 por el doctor Luis Bisquertt, director del Instituto de Educación Física de la Universidad de Chile. En su alocución, titulada "La Educación Física de ahora", sostenía que ésta 
significa persecución y mantenimiento del estado de salud; significa acrecentamiento de las resistencias orgánicas y de la aptitud física y psíquica para el trabajo y la lucha por la vida. Significa también el reforzamiento de la voluntad, de la tenacidad y del dominio de sí mismo (BISQUERTT, 1947, p. 280).

Ahora bien, el predominio conceptual de los aspectos sociales del ejercicio físico no impedía que, coetáneamente, otras formulaciones pedagógicas estuvieran relevando a los aspectos emocionales al observar las interrelaciones entre educación física y carácter o personalidad. Más allá de observar al tratamiento escolarizado del cuerpo como un proceso represivo de fuerzas internas emergentes o una labor de formación de atmósferas emocionales colectivas atravesadas por el fervor patriótico, el educador Demetrio Salas combinaba una mirada de resabios higienistas con una de orden psicológico. En cuanto a la primera, entendía como necesario promover en la juventud estudiantil la desintoxicación, lo que implicaba cuidar el cuerpo evitando consumir carne, alcohol, tabaco, drogas y exponerse al aire contaminado. Respecto a lo segundo, establecía una vinculación sistémica entre emoción y cuerpo, llegando incluso a recomendar que se intentara sustraer a los estudiantes de "las emociones negativas del odio, rencor, la melancolía” por los efectos que ellas tendrían sobre su salud (SALAS, 1941, p. 11).

Así, pues, como parte de este tránsito en que el vínculo entre cuerpo y emoción se hallaba en redefinición, al finalizar la década de 1940 la educación física promovida por el ya aludido Bisquertt se asumía también como "una disciplina espiritual que ayuda y estimula el desarrollo intelectual. Y también representa una función social que, mediante la salud y el contento de vivir que proporciona, facilitará cada vez más, un mayor bienestar de los pueblos, a medida que vaya poniéndose al alcance de las multitudes" (INSTITUTO DE EDUCACIÓN FÍSICA Y TÉCNICA UNIVERSIDAD DE CHILE, 1948, p. 2). Se insinuaban un par de factores que serían importantes en el escenario educativo de posguerra, en lo que a cuerpo y emociones se refiere: la interdependencia (positiva) entre cuerpo, aprendizaje y felicidad y, por otra parte, la continuidad de la preocupación respecto a la salud, formulada ahora en términos de una sociedad de masas en adviento. 


\section{CONCLUSIÓN}

A través del breve recorrido realizado ha sido posible apreciar rearticulaciones de los lazos establecidos en el discurso sobre cuerpo-emoción-educación. Desde un primer horizonte en que las emociones estudiantiles debían ser sofocadas o dirigidas racionalmente, en tanto acciones corporales, a través del cuerpo (deseablemente en perspectiva higiénica y/o patriótica) se nota la expansión de visiones en que la educación física se entiende en relación simbiótica con los aspectos emocionales, pese a que esta lectura no logre alcanzar hegemonía en el período. Cabe señalar que la permeabilidad de las concepciones sobre la educación física ante el discurso psicológico educacional respecto a las emociones fue, en general, creciente en intensidad ya desde el establecimiento profesional de la enseñanza de la educación física en Chile, a inicios del siglo XX, y que experimentó naturales oscilaciones según los focos de lo sanitario o lo patriótico incidieron en los objetivos de para qué se educaba el cuerpo de los jóvenes estudiantes.

\section{REFERENCIAS}

BISQUERTT, L. Educación física social. Santiago: Publicaciones del Boletín de Educación Física de la Universidad de Chile, 1947.

CORBIN, A.; COURTINE, J.-J.; VIGARELLO, G. Histoire du corps. París: Seuil, 2005. v. 2.

DURÁN, S.M. Género, cuerpo, gimnasia y sexualidad en los manuales educacionales higienistas y eugenésicos en chile, 1870-1938. Revista de Historia Social y de las Mentalidades, v. 18, n. 1, p. 35-58, 2014.

HALL, E.T. La dimensión oculta. México: Siglo XXI, 1972.

INSTITUTO DE EDUCACIÓN FÍSICA Y TÉCNICA UNIVERSIDAD DE CHILE. Santiago: Imprenta Cultura, 1948. Folleto.

KEYS, B. The Body as a Political Space: Comparing Physical Education under Nazism and Stalinism. German History, v. 27, n. 3, p. 395-413, 2009. 
MARTÍnEZ, P.G. Metodolojía Especial de la Educación Física. Santiago: Imprenta Universitaria, 1916.

MARTÍNEZ FERNÁNDEZ, F. Construyendo cuerpos infantiles... modelando cuerpos patriotas. La educación física en chile. 1889-1920. Educación Física y Ciencia, n. 13, p. 99-111, 2011.

MATT, S.; STEARNS, P. Doing emotions history. Chicago: University of Illinois Press, 2014.

MATUS, L. El problema de la educación física en Chile y el embrujamiento sueco. Santiago: Imprenta La República, 1932.

PERNAU, M. Space and emotion: building to feel. History Compass, v. 12, n. 7, p. 541-549, 2014.

PLAMPER, J. The history of emotions. An introduction. Oxford: Oxford University Press, 2015.

ROJAS FLORES, J. Los rasgos físicos de los chilenos. In: GÓNGORA, A.; SAGREDO, R. (Orgs.). Fragmentos para una historia del cuerpo en Chile. Santiago: Taurus, 2009. p. 41-117.

SALAS, D. El lugar de la gimnasia en la educación física. Santiago: Imprenta Helvecia, 1941.

SCHARAGRODSKY, P. (Org.). Gobernar es ejercitar. Fragmentos históricos de la Educación Física en Iberoamérica. Buenos Aires: Prometeo, 2008.

SERRANO, S.; PONCE DE LEÓN, M.; RENGIFO, F. Historia de la Educación en Chile (1810-2010). Santiago: Taurus, 2012. v. 2.

SOLOMON, R.C. Ética emocional. Una teoría de los sentimientos. Barcelona: Paidós, 2007.

TABORDA DE OLIVEIRA, M.A. (Org.). Educação do corpo na escola brasileira. Campinas: Editorial Autores Associados, 2006.

TORO BLANCO, P. Close to you: building tutorials relationships at the Liceo in Chile in the long 19th century. Jahrbuch für Historische Bildungsforschung, Berlín, band 18, 2012.

Formar el cuerpo sano y controlar el mal espíritu. Disciplinas del cuerpo y de las emociones juveniles en la educación pública chilena (c.1813-c.1900). In: GAUNE, R.; UNDURRAGA, V. (Orgs.). Formas de control y disciplinamiento. Chile, América y Europa, siglos XVI-XIX. Santiago: Uqbar, 2014. p. 262-279. 
TORO BLANCO, P. La letra ;con sangre entra? Percepciones, normativas y prácticas de disciplinas, castigos y violencias en el liceo chileno, c.1842-c.1912. Santiago: Comisión Bicentenario [Concurso Bicentenario Tesis Doctoral 2007], 2009. v. 2.

. Toy soldiers: The armed body of Chilean students. Military instruction and shooting lessons in schools (Ca. 1880-Ca.1930). Encounters in Theory and History of Education, v. 17, p. 77-91, 2016.

VELASCO, T. El recreo escolar. Maestros adustos y maestros joviales. La Enseñanza, n. 4, p. 168-171, 1903.

\section{NOTAS}

1. La traducción es nuestra.

2. La traducción es nuestra.

3. La traducción es nuestra.

4. Se hace alusión a la teoría desarrollada por el antropólogo norteamericano Edward T. Hall acerca de la proxémica como el conjunto de "las observaciones y teorías interrelacionadas del empleo que el hombre hace del espacio, que es una elaboración especializada de la cultura" (Hall, 1972, p. 6).

5. La traducción es nuestra.

Recebido em 24 de abril de 2017.

Aprovado em 12 de setembro de 2017. 